\title{
Efeito da interação genótipo $\times$ ambiente sobre o peso ao nascimento, aos 205 e aos 550 dias de idade de bovinos da raça Nelore na Região Sul do Brasil
}

\author{
Jader Silva Lopes', Paulo Roberto Nogara Rorato², Tomás Weber ${ }^{3}$, Arione Augusti Boligon4, \\ Juliana Grigoletto Comin ${ }^{5}$, Mariana de Almeida Dornelles ${ }^{5}$
}

\author{
${ }^{1}$ Curso de Graduação em Zootecnia - Departamento de Zootecnia - UFSM. Bolsista PIBIC-CNPq \\ 2 Departamento de Zootecnia da UFSM. \\ ${ }^{3}$ Curso de Pós-Graduação em Zootecnia - Departamento de Zootecnia - UFSM. Bolsista CAPES. \\ ${ }^{4}$ Curso de Pós-Graduação em Genética e Melhoramento Animal - Departamento de Zootecnia - FCAVIUNESP - Jaboticabal, SP. \\ ${ }^{5}$ Curso de Graduação em Zootecnia - Departamento de Zootecnia - UFSM.
}

RESUMO - Com o objetivo de avaliar o efeito da interação genótipo $\times$ ambiente sobre os pesos ao nascimento (PN), à desmama (P205) e ao sobreano (P550), foram analisados registros de peso de 10.874 animais da raça Nelore, filhos de 425 touros e de 7.629 vacas, criados em 46 fazendas nos três estados do Sul do Brasil no período de 1976 a 2001. Os componentes de (co)variância utilizados para estimar os parâmetros genéticos foram obtidos pelo REML, sob modelo animal, em análises uni e bivariadas. Os modelos consideraram aleatórios os efeitos genéticos aditivos direto (PN, P205 e P550) e materno (PN e P205) e o efeito residual e, como fixos, os efeitos de grupo de contemporâneos (PN, P205 e P550), regime alimentar (P205 e P550), condição de criação (P205 e P550), além da idade da vaca ao parto (PN e P205) como covariável, com os efeitos lineares e quadráticos. As herdabilidades diretas para cada estado variaram de 0,38 $\pm 0,04$ a $0,56 \pm 0,08$; de $0,22 \pm 0,03$ a $0,47 \pm 0,05$ e de $0,35 \pm 0,03$ a 0,51 $\pm 0,05$, respectivamente, para PN, P205 e P550; as herdabilidades maternas variaram de $0,19 \pm 0,03$ a $0,31 \pm 0,03$ e de $0,16 \pm 0,08$ a $0,48 \pm 0,07$, respectivamente, para PN e P205. As correlações genéticas estimadas entre os estados foram $0,75 \pm 0,03 ; 0,25 \pm 0,05$; e $0,64 \pm 0,07$ para PN; $0,79 \pm 0,08 ;-0,04 \pm 0,07$; e $0,41 \pm 0,07$ para P205; e $0,53 \pm 0,02 ; 0,08 \pm 0,15$; e 0,76 $\pm 0,09$ para P550, respectivamente, para os estados do Rio Grande do Sul e Santa Catarina, Rio Grande do Sul e Paraná e Santa Catarina e Paraná. De modo geral, as correlações de Spearman entre as DEP preditas nos estados foram baixas e indicam alterações na ordem de classificação dos reprodutores, como conseqüência da interação genótipo $\times$ ambiente.

Palavras-chave: avaliação genética, bovinos de corte, classificação, correlação genética, herdabilidade

\section{Genotype and environment interaction effect on weights at birth, 205 and 550 days of age of Nellore cattle in the South Region of Brazil}

\begin{abstract}
This study aimed to evaluate the genotype $\times$ environment interaction effect on birth (PN), weaning (P205) and yearling (P550) weights of Nellore cattle raised in 46 farms in three states (Rio Grande do Sul-RS, Santa Catarina-SC and Paraná-PR) of the South Region of Brazil, from 1976 to 2001. Records on 10,874 animals, sired by 425 bulls and 7,629 dams were used to estimate (co)variance components by REML. Univariate and bivariate models included the contemporaneous group, feeding type (P205 and P550), management type (P205 and P550), age of cow at calving (PN and P205) covariate (linear and quadratic components) as fixed effects and direct additive genetic (PN, P205 and P550), maternal (PN and P205) and residual as random effects. Direct heritability estimates of PN, P205 and P550 within each State ranged from $0.38 \pm$ 0.04 to $0.56 \pm 0.08$; from $0.22 \pm 0.03$ to $0.47 \pm 0.05$ and from $0.35 \pm 0,03$ to $0.51 \pm 0,05$, respectively. Maternal heritability estimates for the States ranged from $0.19 \pm 0.03$ to $0.31 \pm 0.03$ (PN) and from $0.16 \pm 0.08$ to $0.48 \pm 0.07$ (P205). Genetic correlations for PN, P205 and P550 between states were $0.75 \pm 0.03,0.25 \pm 0.05$ and $0.64 \pm 0.07 ; 0.79 \pm 0.08,-0.04 \pm$ 0.07 and $0.41 \pm 0.07$ and $0.53 \pm 0.02,0.08 \pm 0.15$ and $0.76 \pm 0.09$ respectively for the RS-SC, RS-PR and SC-PR pairs. Overall, the Spearman correlations between breeding values (DEP) for PN, P205 and P550 predicted in different States were low. Changes in sire ranks between states indicate the presence of genotypexenvironment interaction in growth traits of Nellore cattle.
\end{abstract}

Key Words: beef cattle, genetic correlation, genetic evaluation, heritability, sire ranks

Este artigo foi recebido em 22/8/2006 e aprovado em 9/8/2007.

Correspondências devem ser enviadas para rorato@smail.ufsm.br 


\section{Introdução}

O Brasil é um país de proporções continentais, com sistemas heterogêneos de exploração de bovinos determinados, em grande parte, pelas diferenças climáticas e econômicas e pela disponibilidade de recursos naturais relacionados à produção animal. Esta diversidade de ambientes proporciona oportunidades diferentes de expressão para o mesmo genótipo, o que dificulta a identificação de indivíduos geneticamente superiores para a reprodução.

Há basicamente duas proposições na realização da seleção: uma sugere que os animais devem ser selecionados nos melhores ambientes para que possam expressar seu potencial genético (Hammond, 1947); e a outra sugere que o conjunto de genes responsável pela expressão de determinada característica pode variar de acordo com o ambiente a que o genótipo é exposto. Desse modo, a mesma característica em ambientes diferentes pode ser considerada características diferentes (Falconer, 1952).

Considerando que a variação fenotípica é parcialmente controlada pela herança genética, uma vez que a expressão dos genes é afetada pelo meio, e que, com a difusão da inseminação artificial, a utilização de touros se expandiu atingindo diversos ambientes, é necessário que a magnitude da influência do ambiente sobre a produção seja esclarecida. Neste contexto, os estudos relacionados ao efeito da interação genótipo $\times$ ambiente (IGA) sobre o desempenho dos animais assumem maior importância.

Há na literatura diversas definições para IGA, todavia, todas comparam o desempenho de dois ou mais genótipos em pelo menos dois ambientes diferentes (Haldane, 1946; McBride, 1958; Dumlop, 1962). Considerando a teoria de Haldane (1946) e a classificação (rank) dos genótipos em ambientes diferentes, a significância estatística do efeito da interação e os tipos diferentes de interação relatados por Van Vleck et al. (1962; 1963), Pani (1971) propôs a classificação das interações em quatro tipos. No primeiro, apesar das diferenças entre os ambientes, o comportamento dos genótipos é similar e, neste caso, não há interação; no segundo, há uma pequena inversão na ordem de classificação (rank) dos genótipos nos ambientes diferentes, uma vez que neste caso há interação, porém não-significativa; no terceiro, não há inversão na ordem de classificação (rank) dos genótipos, embora o desempenho desses genótipos apresente grandes diferenças nos ambientes diversos. Neste caso, a interação é considerada significativa; finalmente, no quarto tipo, observa-se importante inversão na ordem de classificação (rank) dos genótipos nos ambientes diferentes e a interação é considerada significativa.
$\mathrm{Na}$ atividade produtiva, é importante avaliar a magnitude do efeito desta interação e suas conseqüências econômicas. As avaliações genéticas de bovinos de corte abrangem rebanhos submetidos a grandes variações climáticas e de manejo alimentar e sanitário. Por isso, os rebanhos podem diferir muito na média de produção e nas variâncias fenotípicas e genéticas para as principais características de importância econômica.

Neste estudo, avaliou-se a ocorrência de interação genótipo $\times$ ambiente e seus efeitos sobre as características de desempenho de bovinos da raça Nelore criados em diferentes estados do Sul do Brasil, por meio das estimativas dos coeficientes de herdabilidade, das correlações genéticas e dos valores genéticos preditos.

\section{Material e Métodos}

Para estudar o efeito da IGA sobre as características peso ao nascimento $(\mathrm{PN})$, peso à desmama ajustado para 205 dias de idade (P205) e peso ao sobreano ajustado para 550 dias de idade (P550), foram utilizados registros de desempenho de 10.874 animais nascidos nos estados do Rio Grande do Sul (1.499), Santa Catarina (2.332) e Paraná (7.043) no período de 1976 e 2001. Os animais eram filhos de 425 touros e de 7.629 vacas e foram distribuídos em 46 fazendas participantes do serviço de Controle de Desenvolvimento Ponderal da Associação Brasileira de Criadores de Zebu (ABCZ).

Foram definidos 669 grupos de contemporâneos (GC), constituídos de animais nascidos no mesmo estado, rebanho e ano, em mesma estação, e pertencentes ao mesmo sexo (Tabela 1). O ano foi dividido em duas estações de nascimento, de acordo com as especificidades de clima e o regime de chuvas na Região Sul (abril a setembro e outubro a março). O sistema de criação foi constituído de dois grupos distintos (animais em aleitamento aos 205 dias e animais desmamados aos 205 dias). O regime alimentar foi dividido em três grupos diferentes: o de animais criados extensivamente (59\% dos dados), composto de animais mantidos exclusivamente em pastejo sobre gramíneas recebendo apenas sal proteinado; o de animais em semiconfinamento (30\% dos dados), no qual os animais receberam suplementação com volumoso ou concentrado ou tinham acesso a pastagens consorciadas de gramíneas com leguminosas; e de animais em confinamento ( $11 \%$ ), no qual os animais recebiam toda a alimentação diária (rações, fenos e/ou silagens) no comedouro.

Foram excluídos do arquivo os registros de touros com menos de cinco filhos, as fazendas com menos de 20 animais, os grupos contemporâneos com menos de cinco 
representantes, as vacas com idade ao parto superior a 15 e inferior a dois anos e os touros com filhos em apenas um dos estados.

O efeito da interaçãogenótipo $\times$ ambiente foi avaliado considerando a mesma característica expressa em ambientes diferentes como características distintas determinadas por grupos diferentes de genes, conforme proposto por Falconer (1952). Primeiramente, assumiu-se que a diferença entre as magnitudes das herdabilidades estimadas nos diferentes estados e que as correlações genéticas de baixa magnitude entre os estados, para uma mesma característica, são indícios de IGA.

$\mathrm{O}$ arquivo de trabalho foi dividido em três, cada um com as observações dos filhos de um mesmo grupo de reprodutores em dois dos estados, da seguinte forma: Rio Grande do Sul - Santa Catarina; Rio Grande do Sul - Paraná; e Santa Catarina - Paraná. As correlações genéticas para a mesma característica nos estados diferentes foram estimadas por meio de análises bivariadas. Para estimar as herdabilidades, cada um dos três arquivos foi dividido em dois, de acordo com os estados, e foram realizadas análises univariadas.

Para as análises univariadas, adotou-se um modelo animal que considerou como aleatórios os efeitos genéticos aditivos diretos (para PN, P205 e P550) e maternos (para PN e P205) e o residual; e, como fixos, os efeitos de grupo de contemporâneos (para PN, P205 e P550), regime alimentar (para P205 e P550) e condição de criação (para P205 e P550) e a idade da vaca ao parto como covariável, com os efeitos lineares e quadráticos (para PN e P205). Para as análises univariadas e bivariadas realizadas com o arquivo completo, foi considerado, além dos efeitos descritos, o efeito de estado da federação. O efeito de ambiente permanente da vaca não foi considerado no modelo, uma vez que a média de partos por vaca foi inferior a um parto e meio por vaca (1,45 parto/vaca). O modelo geral de análise utilizado pode ser descrito como:

$$
\mathrm{y}=\mathrm{X} \beta+\mathrm{Z}_{1} \mathrm{a}+\mathrm{Z}_{2} \mathrm{~m}+\mathrm{e},
$$

em que: $y=$ vetor das observações para as características PN, P205 ou P550 em cada estado (análises univariadas) e PN, P205 e P550 da progênie de um mesmo reprodutor em dois estados (análises bivariadas); $\mathrm{X}=$ matriz de incidência associada aos efeitos fixos (grupo de contemporâneos ao nascimento, estado, condição de criação e regime alimen$\operatorname{tar}) ; \beta=$ vetor de soluções para os efeitos fixos; $Z_{1}=$ matriz de incidência associada aos efeitos genéticos aditivos diretos; $Z_{2}=$ matriz de incidência associada aos efeitos genéticos aditivos maternos; $\mathrm{a}=$ vetor de efeitos genéticos aditivos diretos do animal; $\mathrm{m}=$ vetor de efeitos genéticos aditivos maternos; $\mathrm{e}=$ vetor dos resíduos.

Os componentes de (co)variância utilizados para estimar os parâmetros e os valores genéticos foram obtidos pelo Método da Máxima Verossimilhança Restrita livre de derivada utilizando-se o aplicativo MTDFREML (Boldman et al., 2001).Aplicou-se um algoritmo simplex para obtenção de $-2 \log$ da função de verossimilhança. Os valores dos

Tabela 1 - Número de observações (N), número de pais (NP), número de filhos por pai, média (Med), mínimo (Min) e máximo (Max), número de mães (NM), número de grupos de contemporâneos (GC), número de fazendas (FA), número de sistemas de criação (SC) e número de regimes alimentares (RA) avaliados nos estados (EF) e com a característica estudada para a raça Nelore

\begin{tabular}{|c|c|c|c|c|c|c|c|c|c|c|}
\hline \multirow[t]{2}{*}{$\mathrm{EF}$} & \multirow[t]{2}{*}{$\mathrm{N}$} & \multirow[t]{2}{*}{ NP } & \multicolumn{3}{|c|}{ Número de filhos/pai } & \multirow[t]{2}{*}{ NM } & \multirow[t]{2}{*}{ GC } & \multirow[t]{2}{*}{ FA } & \multirow[t]{2}{*}{$\mathrm{SC}$} & \multirow[t]{2}{*}{ RA } \\
\hline & & & Méd & Min & $\operatorname{Max}$ & & & & & \\
\hline \multicolumn{11}{|c|}{ Peso ao nascer (PN) } \\
\hline RS & 864 & 47 & 18 & 2 & 54 & 560 & 60 & 10 & - & - \\
\hline SC & 806 & 36 & 22 & 2 & 62 & 658 & 58 & 8 & - & - \\
\hline PR & 7.043 & 77 & 91 & 2 & 274 & 4.646 & 422 & 20 & - & - \\
\hline *Total & 8.713 & 160 & 54 & 2 & 274 & 5.864 & 540 & 38 & - & - \\
\hline \multicolumn{11}{|c|}{ Peso à desmama (P205) } \\
\hline RS & 596 & 40 & 15 & 2 & 48 & 428 & 54 & 8 & 2 & 3 \\
\hline $\mathrm{SC}$ & 654 & 30 & 21 & 2 & 64 & 552 & 66 & 8 & 2 & 3 \\
\hline PR & 5874 & 72 & 81 & 2 & 260 & 4.192 & 446 & 20 & 2 & 3 \\
\hline *Total & 7.124 & 142 & 50 & 2 & 260 & 5.172 & 566 & 36 & 2 & 3 \\
\hline \multicolumn{11}{|c|}{ Peso ao sobreano (P550) } \\
\hline RS & 669 & 44 & 15 & 2 & 52 & 459 & 49 & 7 & 1 & 2 \\
\hline SC & 706 & 32 & 22 & 2 & 114 & 585 & 61 & 7 & 1 & 3 \\
\hline PR & 6.437 & 73 & 88 & 8 & 259 & 4.362 & 445 & 20 & 2 & 3 \\
\hline *Total & 7.818 & 149 & 52 & 2 & 259 & 5.412 & 555 & 34 & 2 & 3 \\
\hline$* * \mathrm{AC}$ & 10.864 & 425 & 26 & 2 & 274 & 7.629 & 669 & 46 & 2 & 3 \\
\hline
\end{tabular}

${ }^{*}$ Total $=$ total por característica $;{ }^{* *} \mathrm{AC}=$ total para 0 arquivo completo . 
componentes de (co)variância que minimizam a função -2 Log da função de verossimilhança são as estimativas de máxima verossimilhança desses componentes. O critério deconvergência considerado foi $10^{-6}$, repetindo-se as análises do quanto necessário para que a diferença entre as estimativas permanecesse menor que $10^{-6}$, sempre utilizando os valores das análises anteriores.

As pressuposições assumidas em relação aos vetores $y, a, m$ e $e$ nas análises bivariadas foram:

$$
\begin{gathered}
\mathrm{E}[\mathrm{y}]=\mathrm{X} \beta ; \operatorname{Var}(\mathrm{a})=\mathrm{A} \otimes \mathrm{G}_{\mathrm{a}}, \operatorname{Var}(\mathrm{m})=\mathrm{A} \otimes \mathrm{G}_{\mathrm{m}}, \operatorname{Var}(\mathrm{e})= \\
\mathrm{I} \otimes \mathrm{R}_{\mathrm{e}},
\end{gathered}
$$

em que $\mathrm{G}_{\mathrm{a}}=$ matriz de covariâncias genéticas aditivas; $\mathrm{G}_{\mathrm{m}}=$ a matriz de covariâncias genéticas maternas; $\mathrm{R}_{\mathrm{e}}=$ matriz de covariância residual; $\mathrm{A}=$ matriz do numerador de relações genético-aditivas; $\mathrm{I}=$ matriz identidade; e $\otimes=$ produto direto entre matrizes. Assumiu-se ainda que os vetores $a, m$ e $e$ são não-correlacionados entre si. Para as análises univariadas, as pressuposições assumidas foram:

$$
\begin{gathered}
\mathrm{E}(y)=\mathrm{X} \beta, \mathrm{E}(\mathrm{a})=\mathrm{E}(m)=\mathrm{E}(e)=0, \operatorname{Var}(y)=\mathrm{Z}_{1} \mathrm{AZ}{ }_{1}{ }^{\prime} \sigma_{a}^{2} \\
+Z_{2} A Z_{2} \sigma_{m}^{2}+\mathrm{R}, \operatorname{Var}(\mathrm{a})=\mathrm{A} \sigma_{a}^{2}, \operatorname{Var}(m)=\mathrm{A} \sigma_{m}^{2}, \\
\operatorname{Var}(\mathrm{e})=\mathrm{I} \sigma_{e}^{2},
\end{gathered}
$$

em que: $\mathrm{A}=$ matriz de parentesco, $\mathrm{I}=$ matriz identidade, $\mathrm{R}=$ matriz de variâncias e covariâncias residuais, $\sigma_{a}^{2}=$ componente de variância genética aditiva direta, $\sigma_{m}^{2}=$ componente de variância genética aditiva materna, $\sigma_{e}^{2}=$ componente de variância residual.

Outra forma de avaliar o efeito da IGA foi por meio da mudança na ordem de classificação dos reprodutores. Os reprodutores foram classificados (rank) com base na média de produção de suas progênies (DEP) nos três arquivos, agrupando os estados dois a dois. A similaridade entre a classificação para os reprodutores nos dois estados foram avaliadas por meio da correlação de Spearman (SAS, 2001) considerando três pressões de seleção distintas, 10, 20 e $30 \%$.

\section{Resultados e Discussão}

A maior média para PN ocorreu no Paraná $(30,44 \pm$ $2,43 \mathrm{~kg}$ ) e foi $2 \%$ maior que a verificada em Santa Catarina $(29,12 \pm 2,88 \mathrm{~kg})$. A média obtida no Paraná foi superior à observada por Cubas et al. (2001) para esta mesma raça no mesmo estado $(28,50 \pm 0,38 \mathrm{~kg})$. A maior média para P205 ocorreu no Rio Grande do Sul $(177,66 \pm 30,68 \mathrm{~kg})$ e foi $14 \%$ superior à observada em Santa Catarina $(151,97 \pm 33,11 \mathrm{~kg})$. As médias observadas nos três estados foram próximas às encontradas na raça Nelore por Eler et al. (2000) para o Sudeste e Centro-Oeste brasileiro e por Toral et al. (2004) para o Mato Grosso do Sul; todavia, são superiores às relatadas por Cubas et al. (2001) para o PR (141,30 $\pm 1,47 \mathrm{~kg}) \mathrm{e}$ inferiores às relatadas por Ferreira et al. (2001) para o estado de Minas Gerais (189,38 $\pm 28,25$ e 183,62 $\pm 32,76)$, também com a mesma raça. O maior valor para P550 foi observado no Rio Grande do Sul $(331,97 \pm 25,78 \mathrm{~kg})$ e foi $9 \%$ maior que o menor valor observado em Santa Catarina $(303,35 \pm 24,41 \mathrm{~kg})$. Os menores pesos para as três características foram observados em Santa Catarina, apesar de o PN no Rio Grande do Sul ter sido praticamente o mesmo que o verificado em Santa Catarina. O P205 e o P550 foram, respectivamente, 4 e $2 \%$

\begin{tabular}{|c|c|c|c|c|}
\hline & & $\mathrm{PN}$ & P205 & P550 \\
\hline \multirow[t]{4}{*}{ Rio Grande do Sul } & Número de observações & 1.499 & 1.087 & 869 \\
\hline & Peso médio (kg) & 29,85 & 177,66 & 331,97 \\
\hline & Desvio-padrão (kg) & 2,96 & 30,68 & 85,59 \\
\hline & $\mathrm{CV}(\%)$ & 9,92 & 17,27 & 25,78 \\
\hline \multirow[t]{4}{*}{ Santa Catarina } & Número de observações & 2.332 & 2.018 & 1.847 \\
\hline & Peso médio (kg) & 29,12 & 151,97 & 303,35 \\
\hline & Desvio-padrão (kg) & 2,88 & 33,11 & 77,07 \\
\hline & $\mathrm{CV}(\%)$ & 9,89 & 21,79 & 24,41 \\
\hline \multirow[t]{4}{*}{ Paraná } & Número de observações & 7.043 & 5.847 & 5.237 \\
\hline & Peso médio $(\mathrm{kg})$ & 30,44 & 170,38 & 325,97 \\
\hline & Desvio-padrão (kg) & 2,43 & 29,02 & 81,97 \\
\hline & $\mathrm{CV}(\%)$ & 7,98 & 17,03 & 25,15 \\
\hline Arquivo completo & Peso médio $(\mathrm{kg})$ & 29,80 & 166,67 & 320,43 \\
\hline
\end{tabular}
maiores no Rio Grande do Sul em relação ao Paraná. Os menores coeficientes de variação $(\mathrm{CV})$ para as três caracte-

Tabela 2 - Número de observações, peso médio, desvio-padrão e coeficiente de variação para os pesos ao nascimento (PN), à desmama (P205) e ao sobreano (P550) da raça Nelore na Região Sul 
rísticas ocorreram no Paraná e os maiores em Santa Catarina. Entretanto, apesar de o coeficiente de variação para PN ter sido $20 \%$ menor no Paraná em relação ao Rio Grande do Sul, essa diferença foi de apenas 1 e $2 \%$, respectivamente, para P205 e P550.

As estimativas de herdabilidade direta obtidas por análises univariadas (Tabela 3) para PN variaram de $0,38 \pm 0,04$ (completo) a 0,56 $\pm 0,08$ (Rio Grande do Sul) e estão no intervalo $(0,16$ a 0,66$)$ observado por Toral et al. (2004) em três microrregiões do Mato Grosso do Sul e por Machado et al. (1999) e Eler et al. (2000) para a raça Nelore. Para P205, as estimativas de herdabilidade variaram de 0,22 $\pm 0,03$ (Paraná) a 0,47 $\pm 0,05$ (Rio Grande do Sul) e foram próximas aos valores relatados porEler et al. (2000), Ferreira et al. (2001) e Toral et al. (2004), de 0,16 a 0,59; entretanto, são superiores aos descritos por Ribeiro et al. (2001), 0,16, e Silveira et al. (2004), 0,17, para a mesma raça. Para P550, as estimativas de herdabilidades variaram de 0,35 $\pm 0,03$ (Paraná) a 0,51 $\pm 0,05$ (Rio Grande do Sul) e corroboram parcialmente os valores relatados por Toral et al.(2004), de 0,35 a 0,45 . No entanto, foram superiores às obtidas por Ferreira et al. (2001), 0,17, e Ribeiro et al. (2001), 0,76, para a raça Nelore. As maiores estimativas de herdabilidade para as três características estudadas foram observadas no Rio Grande do Sul e comprovam efeito menor do ambiente sobre o desempenho nas condições de criação adotadas, no entanto, o menor número de observações coletadas em menor número de propriedades com manejo mais homogêneo neste estado pode ter reduzido a variância de ambiente e superestimado esses valores.

As diferenças entre as magnitudes das estimativas de herdabilidade de um estado para outro foram 7, 12 e 7\% para PN; 13, 53 e 22\% para P205 e 16, 29 e 11\% para P550, respectivamente, para os arquivos Rio Grande do Sul Santa Catarina, Rio Grande do Sul - Paraná e Santa Catarina - Paraná. A maior diferença foi observada sempre para o arquivo Rio Grande do Sul - Paraná, onde os ambientes são mais contrastantes. Essas altas estimativas indicam que grande parte da variação fenotípica na população estudada está relacionada aos efeitos aditivos dos genes, o que possibilita obter ganho genético considerável por meio da seleção. Entretanto, a diferença na magnitude dessas estimativas sugere que a resposta fenotípica das progênies de um mesmo reprodutor é diferente nos três estados.

A habilidade materna expressa a capacidade da vaca em criar suas progênies, por isso, assume grande importância nos programas de seleção. As estimativas de herdabilidade materna obtidas por análises univariadas (Tabela 3) para PN variaram de $0,19 \pm 0,03$ (Paraná) a 0,31 $\pm 0,03$ (completo) e são superiores aos valores relatados por Eler et al. (2000), de 0,03 a 0,09. Para P205, as estimativas variaram de 0,16 $\pm 0,06$ (Santa Catarina) a 0,48 $\pm 0,07$ (Rio Grande do Sul) e corroboram, em parte, as obtidas por Ribeiro et al. (2001), de 0,16. Entretanto, foram superiores às obtidas por Eler et al. (2000), Ferreira et al. (2001) e Silveira et al. (2004), que variaram de 0,06 a 0,15 . A diferença entre a maior e a menor estimativa para PN entre os estados foi de seis pontos percentuais, o que significa que a diferença de ambiente entre os estados não exerceu grande influência sobre o efeito materno no período pré-natal; todavia, esta diferença para P205 foi de 32 pontos percentuais e comprova que houve maior influência no período pós-natal. As diferenças entre as magnitudes destas estimativas de um estado para outro foram 16 , 4 e $24 \%$ para $\mathrm{PN}$ e de 47,60 e $11 \%$ para $\mathrm{P} 205$, respectivamente, para os arquivos RS-SC, RS-PR e SC-PR. Esses valores sugerem que a habilidade materna é afetada pelo ambiente e que as filhas de um mesmo reprodutor tendem a apresentar desempenhos diferentes, em maior magnitude para P205, nos diferentes estados.

As correlações genéticas (Tabela 3) entre os desempenhos das progênies de um mesmo reprodutor nos diferentes estados variaram de 0,25 0,05 (Rio Grande do Sul e Paraná) a 0,75 $\pm 0,03$ (Rio Grande do Sul e Santa Catarina) para PN; de -0,04 $\pm 0,07$ (Rio Grande do Sul e Paraná) a 0,79 $\pm 0,08$ (Rio Grande do Sul e Santa Catarina) para P205 e de 0,08 \pm 0,15 (Rio Grande do Sul eParaná) a 0,76 0,09 (Santa Catarina e Paraná) para P550. As menores correlações genéticas foram observadas entre Rio Grande do Sul e Paraná,estados com condições de ambiente mais contrastantes, especialmente se comparadas às regiões oeste e noroeste do Paraná com o Rio Grande do Sul.Essas estimativas diferem, em magnitude, daquelas relatadas por Toral et al. (2004), em torno de 0,32, para a raça Nelore em diferentes microrregiões do estado de Mato Grosso do Sul e por Fridrichet al. (2003)para a raça Tabapuã entre as regiões Sul e Nordeste $(-0,86)$. Entretanto, nesses trabalhos, as correlações genéticas inferiores a 0,80 , de acordo com o proposto por Robertson (1959), evidenciam a ocorrência da IGA. Correlação genética baixa significa que os genes relacionados ao crescimento em um estado não são os mesmos genes responsáveis pela expressão desta característica no outro estado. Esses resultados indicam que a inclusão da região de nascimento no modelo de análise para avaliações genéticas aumenta a acurácia da predição do valor genético e sugerem que avaliações genéticas por estado talvez sejam mais eficientes para identificar animais geneticamente superiores.

As correlações de Spearman entre as classificações (rank) dos reprodutores com base nas DEP preditas nos 
Tabela 3 - Estimativas de herdabilidades direta $\left(h^{2}{ }_{a}\right)$ e materna $\left(h^{2}{ }_{m}\right)$ e de correlação genética $\left(r_{g}\right)$ para peso ao nascimento $(P N)$, à desmama (P205) e ao sobreano (P550) para a raça Nelore na Região Sul

\begin{tabular}{|c|c|c|c|c|c|c|c|}
\hline \multicolumn{8}{|c|}{ Peso ao nascer (PN) } \\
\hline & \multicolumn{2}{|c|}{ Rio Grande do Sul e Santa Catarina } & \multicolumn{2}{|c|}{ Rio Grande do Sul e Paraná } & \multicolumn{2}{|c|}{ Santa Catarina e Paraná } & Completo \\
\hline $\begin{array}{l}\mathrm{h}^{2}{ }^{*} \\
\mathrm{~h}^{\mathrm{a}^{\mathrm{a}}}{ }_{\mathrm{m}}^{*}\end{array}$ & $\begin{array}{l}0,56 \pm 0,08 \\
0,21 \pm 0,08\end{array}$ & $\begin{array}{l}0,52 \pm 0,03 \\
0,25 \pm 0,07\end{array}$ & $\begin{array}{l}0,51 \pm 0,06 \\
0,22 \pm 0,07\end{array}$ & $\begin{array}{l}0,45 \pm 0,04 \\
0,23 \pm 0,02\end{array}$ & $\begin{array}{l}0,43 \pm 0,05 \\
0,25 \pm 0,06\end{array}$ & $\begin{array}{l}0,40 \pm 0,03 \\
0,19 \pm 0,03\end{array}$ & $\begin{array}{l}0,38 \pm 0,04 \\
0,31 \pm 0,03\end{array}$ \\
\hline$r_{g}$ & \multirow{2}{*}{\multicolumn{2}{|c|}{$0,75 \pm 0,03$}} & \multicolumn{2}{|c|}{$0,25 \pm 0,05$} & \multicolumn{2}{|c|}{$0,64 \pm 0,07$} & - \\
\hline $\mathrm{N}$ & & & \multicolumn{2}{|c|}{8.542} & \multicolumn{2}{|c|}{9.375} & 10.874 \\
\hline NR & \multicolumn{2}{|c|}{$\begin{array}{c}3.831 \\
103\end{array}$} & \multirow{2}{*}{\multicolumn{2}{|c|}{13.422}} & \multirow{2}{*}{\multicolumn{2}{|c|}{$\begin{array}{c}295 \\
16.031\end{array}$}} & 425 \\
\hline $\mathrm{A}^{-1}$ & \multicolumn{2}{|c|}{7.809} & & & & & 18.269 \\
\hline \multicolumn{8}{|c|}{ Peso à desmama (P205) } \\
\hline & \multicolumn{2}{|c|}{ Rio Grande do Sul e Santa Catarina } & \multicolumn{2}{|c|}{ Rio Grande do Sul e Paraná } & \multicolumn{2}{|c|}{ Santa Catarina e Paraná } & Total \\
\hline $\begin{array}{l}\mathrm{h}^{2}{ }^{*} \\
\mathrm{~h}^{2}{ }_{\mathrm{m}}{ }^{*}\end{array}$ & $\begin{array}{l}0,47 \pm 0,05 \\
0,16 \pm 0,08\end{array}$ & $\begin{array}{l}0,41 \pm 0,04 \\
0,30 \pm 0,08\end{array}$ & $\begin{array}{l}0,47 \pm 0,05 \\
0,48 \pm 0,07\end{array}$ & $\begin{array}{l}0,22 \pm 0,03 \\
0,19 \pm 0,04\end{array}$ & $\begin{array}{l}0,41 \pm 0,04 \\
0,16 \pm 0,06\end{array}$ & $\begin{array}{l}0,32 \pm 0,04 \\
0,18 \pm 0,05\end{array}$ & $\begin{array}{l}0,28 \pm 0,05 \\
0,20 \pm 0,03\end{array}$ \\
\hline$r_{g}$ & \multicolumn{2}{|c|}{$0,79 \pm 0,08$} & \multicolumn{2}{|c|}{$-0,04 \pm 0,07$} & \multicolumn{2}{|c|}{$0,41 \pm 0,07$} & - \\
\hline $\mathrm{N}$ & \multicolumn{2}{|c|}{3.105} & \multicolumn{2}{|c|}{6.934} & \multicolumn{2}{|c|}{7.865} & 8.952 \\
\hline NR & \multirow{2}{*}{\multicolumn{2}{|c|}{$\begin{array}{c}95 \\
5.121\end{array}$}} & \multirow{2}{*}{\multicolumn{2}{|c|}{274}} & \multicolumn{2}{|c|}{281} & 382 \\
\hline$A^{-1}$ & & & & & \multicolumn{2}{|c|}{13.980} & 15.515 \\
\hline \multicolumn{8}{|c|}{ Peso ao sobreano (P550) } \\
\hline & \multicolumn{2}{|c|}{ Rio Grande do Sul e Santa Catarina } & \multicolumn{2}{|c|}{ Rio Grande do Sul e Paraná } & \multicolumn{2}{|c|}{ Santa Catarina e Paraná } & Total \\
\hline $\mathrm{h}_{\mathrm{a}}^{2} *$ & $0,51 \pm 0,05$ & $0,43 \pm 0,04$ & $0,49 \pm 0,04$ & $0,35 \pm 0,03$ & $0,45 \pm 0,03$ & $0,40 \pm 0,05$ & $0,47 \pm 0,03$ \\
\hline$r_{g}$ & \multicolumn{2}{|c|}{$0,53 \pm 0,02$} & \multicolumn{2}{|c|}{$0,08 \pm 0,15$} & 0,76 & 0,09 & - \\
\hline$N^{2}$ & & & & & & & 7.953 \\
\hline NR & & & & & & & 356 \\
\hline$A^{-1}$ & & & & & & & 13.629 \\
\hline
\end{tabular}

$r_{g}=$ correlação genética entre as características consideradas distintas em cada estado; $N$ = número de observações; $N R=$ número de reprodutores $\mathrm{A}^{-1}=$ matriz de parentesco; *Herdabilidades estimadas por meio de análises univariadas.

diferentes estados, considerando três intensidades de seleção distintas, variaram de 0,11 (Rio Grande do Sul e Paraná) a 0,75 (Santa Catarina e Paraná) para PN; de 0,15 (Rio Grande do Sul e Paraná) a 0,41 (Santa Catarina e Paraná) para P205; e de 0,12 (Rio Grande do Sul e Paraná) a 0,51 (Santa Catarina e Paraná) para P550 (Tabela 4). Esses valores indicam que as diferenças de ambiente nos diferentes estados promoveram mudanças na ordem relativa de classificação dos touros avaliados geneticamente. $\mathrm{O}$ mesmo foi observado por Toral et al. (2004) para diferentes regiões do Mato Grosso do Sul e por Alencar et al. (2005) para a raça Canchim no estado de São Paulo. Assim, é evidente que um reprodutor mais adequado para um estado não o é, necessariamente, para o outro. Considerando a intensidade de seleção de 10\% (Tabela 4), o valor máximo de coincidência entre a classificação de um reprodutor em dois estados foi de apenas $35 \%$, portanto, houve $65 \%$ de probabilidade de os filhos desses reprodutores apresentarem desempenhos diferenciados. O valor mínimo para a correlação de ordem ocorreu sempre para o conjunto de dados Rio Grande do Sul e Paraná para as três intensidades de seleção $(10,20$ e $30 \%)$ consideradas.

O sucesso de um programa de melhoramento genético animal depende da proporção do ganho genético transferido
Tabela 4 - Correlações de Spearman entre as classificações (rank) das DEP preditas para os os 10, 20 e $30 \%$ melhores reprodutores nos três estados da Região Sul do Brasil

\begin{tabular}{lccc}
\hline & PN & P205 & P550 \\
\hline \multicolumn{3}{c}{$10 \%$ melhores } \\
\hline RS-SC & 0,32 & 0,21 & 0,35 \\
RS-PR & 0,11 & 0,15 & 0,12 \\
SC-PR & 0,35 & 0,18 & 0,31 \\
\hline \multicolumn{3}{c}{$20 \%$ melhores } \\
\hline RS-SC & 0,51 & 0,25 \\
RS-PR & 0,15 & 0,17 & 0,41 \\
SC-PR & 0,42 & 0,22 & 0,48 \\
\hline \multicolumn{3}{c}{$30 \%$ melhores } \\
\hline RS-SC & 0,68 & 0,33 & 0,45 \\
RS-PR & 0,24 & 0,21 & 0,28 \\
SC-PR & 0,75 & 0,41 & 0,51 \\
\hline
\end{tabular}

RS = Rio Grande do Sul, SC = Santa Catarina, $P R=$ Paraná PN = peso ao nascimento; P205 = peso ajustado para 205 dias de idade; $P 550=$ peso ajustado para 550 dias de idade.

de uma geração para outra. Os resultados deste trabalho sugerem que, quando o processo de mudança na média da população é incrementado por reprodutores e/ou sêmen procedentes de outros criatórios, deve ser dispensada atenção especial ao ambiente de origem deste material 
genético, pois, quanto maior a semelhança entre os ambientes, melhor a resposta fenotípica do material genético imigrante. Portanto, caso a interação genótipo $\times$ ambiente não seja considerada, pode ocorrer a escolha de reprodutores inadequados, o que prejudica o progresso genético na população em seleção.

\section{Conclusões}

Houve interação genótipo $\times$ ambiente nas populações estudadas, portanto, é necessário considerar esse efeito nas avaliações genéticas para características de desempenho da Região Sul do Brasil. Considerando a importância do tema e o volume relativamente pequeno de dados utilizados neste estudo, recomenda-se que outras pesquisas sejam realizadas com amostras mais representativas.

\section{Literatura Citada}

ALENCAR, M.M.; MASCIOLI, A.S.; FREITAS, A.R. Evidências de interação genótipo $\times$ ambiente sobre características de crescimento em bovinos de corte. Revista Brasileira de Zootecnia, v.34, n.2, p.489-495, 2005.

BOLDMAN, K.H.; KRIESE, L.A.; Van VLECK, L.D. et al. A manual for use for MTDFREML. A set of programs to obtain estimates of variance and covariances (Draft). Lincoln: Departament of Agriculture/Agricultural Research Service, 2001. 120p.

CUBAS, A.C.; PEROTTO, D.; ABRAHÃO, J.J.P. Desempenho até a desmama de bezerros Nelore e cruzados com Nelore. Revista Brasileira de Zootecnia, v.30, n.3 p.694-701, 2001.

DUMLOP, A.A. Interaction between heredity and environment in the Australian Merino. I. Strain x location interactions in wool traits. Australian Journal of Agricultural Research, v.13, p.503-531, 1962

ELER, J.P.; FERRAZ, J.B.S.; GOLDEN, B.L. et al. Influência da interação touro $\times$ rebanho na estimação da correlação entre efeitos genéticos direto e materno em bovinos da raça Nelore. Revista Brasileira de Zootecnia, v.29, n.6, p.1642-1648, 2000 .
FERREIRA, V.C.P.; PENA, V.M.; BERGMANN, J.A.G. et al. Interação genótipo-ambiente em algumas características produtivas de gado de corte no Brasil. Arquivo Brasileiro de Medicina Veterinária e Zootecnia, v.53, n.3, p.385-392, 2001.

FALCONER, D.S. The problem of environment and selection. American Naturalist, v.86, p.293-298, 1952.

FRIDRICH, A.B.; SILVA, M.A.; FRIDRICH, D. et al. Interação genótipo $\times$ ambiente em algumas características de produção de bovinos de corte da raça Tabapuã. In: REUNIÃO ANUAL DA SOCIEDADE BRASILEIRA DE ZOOTECNIA, 40., 2003, Santa Maria. Anais... Santa Maria: Sociedade Brasileira de Zootecnia, 2003.

HALDANE, J.B.S. The interaction of nature and nurture. Annals of Eugenics, v.13, p.197-205, 1946.

HAMMOND, J. Animal breeding in relation to nutrition and environment conditions. Journal of Animal Science, v.22, n.2, p.195-213, 1947.

MCBRIDE, C. The environment and animal breeding problems. Animal Breeding Abstract, v.26, n.4, p.349-358, 1958.

MACHADO, P.F.A.; AQUINO, L.H.; GONÇALVES, T.M. Estimativas de parâmetros genéticos e critérios de seleção em características ponderais de bovinos Nelore. Ciência e Agrotecnia, v.23, n.1, p.197-204, 1999.

PANI, S.N. Genetic $x$ environment interaction in sire evaluation. Missouri: 1971. 138p.

RIBEIRO, M.N.; PIMENTA FILHO, E.C.; MARTINS, G.A. et al. Herdabilidade para efeitos direto e materno de características de crescimento de bovinos Nelore no estado da Paraíba. Revista Brasileira de Zootecnia, v.30, n.4, p.1224-1227, 2001.

ROBERTSON, A. The sampling variance of genetic correlation coefficient. Biomethic, v.15, p.469-485, 1959.

ST ATISTICAL ANALYSIS SYSTEMS - SAS. User's guide: Stat, Version 8 ed. Cary: 2001. (CD-ROM).

SILVEIRA, J.C.; McMANUS, C.; MACIOLI, A.S. et al. Fatores ambientais e parâmetros genéticos para características produtivas e reprodutivas em um rebanho Nelore no estado do Mato Grosso do Sul. Revista Brasileira de Zootecnia, v.33, n.6, p.1432-1444, 2004.

TORAL, F.L.B.; SILVA, L.O.C.; MARTINS, E.N. et al. Interação genótipo $\times$ ambiente em características de crescimento de bovinos da raça Nelore no Mato Grosso do Sul. Revista Brasileira de Zootecnia, v.33, n.6, p.1445-1455, 2004.

Van VLECK, L.D. Genotype and environment in sire evaluation. Journal of Dairy Science, v.46, p.983-989, 1963.

Van VLECK, L.D.; KING, S.C.; DOLITTLE, D.P. Sources of variations in the Cornell controls at two locations. Poultry Science, v.42, p.1114-1125, 1962. 